This document is the accepted manuscript version of the following article:

Lin, C., Yan, Y., Liu, Z., Ke, H., Qiu, Z., \& Hufenus, R. (2019). Flexible phase change filament with ionic 1iquid core. Journal of Applied Polymer Science, 136(32), 47830 (9 pp.). https://doi.org/10.1002/app.47830

\title{
Flexible Phase Change Filament with Ionic Liquid Core
}

Chao Lin ${ }^{1}$, Yurong Yan ${ }^{1,}$, Zhengyu Liu ${ }^{1}$, Hanhan $\mathrm{Ke}^{1}$, Zhiming Qiu ${ }^{1}$, Rudolf Hufenus $^{2}$

1 School of Materials Science and Engineering, South China University of Technology, Guangzhou, China, 510640

2 Empa, Swiss Federal Laboratories for Materials Science and Technology, St. Gallen, Switzerland

*corresponding author: Yurong Yan

E-mail address: yryan@scut.edu.cn 
Abstract:

A flexible phase change filament with core-sheath structure was successfully prepared by post-filling of a polypropylene (PP) hollow fiber. The ionic liquid (IL) 1butyl-4-methylpyridinium hexafluorophosphate was chosen as core component while copper decorated muscovite (Cu-MVT) was synthesized via in situ reduction and used as the refining additive for the IL. Results from differential scanning calorimetry (DSC) demonstrated that the encapsulation ratio of the flexible phase change filament reached $93 \%$ with a fusion latent heat of $52.7 \mathrm{~J} / \mathrm{g}$ at $48.3{ }^{\circ} \mathrm{C}$. Supercooling of the ionic liquid was suppressed effectively as shown by the crystallization in the cooling step due to the addition of $\mathrm{Cu}-\mathrm{MVT}$. The flexible phase change material with core-sheath structure also showed good thermal stability, durability and mechanical property under the protection of the sheath polymer material. It is evident that the phase change filament possesses promising characteristics for thermal energy storage and thermoregulation. 


\section{Introduction}

Due to their thermal storage and thermoregulation properties, phase change materials (PCMs) have been widely applied in heating of buildings, solar energy storage, smart materials, packaging of temperature-sensitive materials and technical textiles (e.g. medical bandages, outdoor wear, space suits, etc.) ${ }^{[1-4]}$.

PCMs achieve thermoregulation by absorbing or releasing heat within a narrow temperature range during phase change process ${ }^{[3,5]}$. Traditional solid-liquid type PCMs include organic and inorganic materials. Inorganic $\mathrm{PCMs}\left(\mathrm{KNO}_{3}, \mathrm{NaCO}_{3} \cdot 10 \mathrm{H}_{2} \mathrm{O}\right.$, etc.) offer large latent heat, high thermal conductivity and small volume change, but thermal storage ability can be insufficient due to phase separation and supercooling ${ }^{[6]}$. Inorganic salts can also be corrosive. Organic PCMs (paraffin waxes, polyethylene glycols, fatty acids, etc.), on the other hand, are chemically stable without showing phase separation. But they also have limitations such as volatility, flammability and low thermal conductivity. In contrast, ionic liquids (ILs) are salts that are liquid at or near room temperature, being composed of organic cations and inorganic or organic anions. ILs have gained popularity as green solvents in early days ${ }^{[7,8]}$. Their application in heat storage has been investigated recently due to their tunable melting point, volume stability, nonvolatility and nonflammability $[\underline{2}, \underline{10}]$. ILs are potential alternatives for common thermal storage materials.

Despite many advantages that ILs can offer as heat storage agents, some problems still need to be solved. For most materials, the crystallization point is close to the melting point. However, the crystallization point of ILs is much lower than their melting 
51 point. The temperature difference of ILs can reach more than $100 \mathrm{~K}[\underline{11}, \underline{12}]$. This 52 supercooling phenomenon leads either to a lower temperature or to a broader temperature range of latent heat release, which hampers the heat storage application of ILs. This problem can be addressed by adding nucleating agents, which is a simple and effective way to promote crystallization and to lower the degree of supercooling. Bai et al. ${ }^{[13]}$ studied the effects of the nucleating agents (copper and graphene) on the thermodynamic properties of $\left[\mathrm{C}_{16} \mathrm{MIM}\right] \mathrm{Br}$ and $\left[\mathrm{C}_{16} \mathrm{MMIM}\right] \mathrm{Br}$. Results showed that the degree of supercooling was decreased by $1 \sim 3 \mathrm{~K}$. Compared to synthetic nucleating agents, natural minerals are more promising economically and ecologically, and can be easily applied to PCM systems $[14,15]$. Muscovite (MVT), a kind of aluminosilicate mineral, has been widely used as reinforcing filler in polymeric composites due to its excellent thermal, mechanical and electrical properties ${ }^{[16]}$. MVT has a layered structure that can provide a huge specific surface for nucleation. However, there are few reports on using muscovite as nucleating agent for PCMs.

Another problem to be addressed is that the properties of ILs are sensitive to impurities, especially water. ILs, even hydrophobic type, adsorb water from air, increasing their degree of supercooling, or even making them lose the crystallization property $[\underline{17}, \underline{18}]$. To prevent ILs from impurity pollution, as well as to avoid leakage when them melt, ILs must be appropriately encapsulated. Common PCMs packing methods include polymer melt blending [19], inorganic porous material loading [20], microencapsulation ${ }^{[21}, \underline{22]}$ and core-sheath compounding ${ }^{[23]}$. Polymer melt blending and inorganic porous material loading are easy to operate, but the final product has a semi- 
closed structure where PCMs is still exposed to air, thus it is not suitable for IL-based PCMs. Microencapsulation of organic PCMs has frequently been reported [24-27], but this method is rather complex and generate high costs. As water-based emulsions or suspensions are usually used to prepare the polymeric shell, microencapsulation is not applicable for water-sensitive ILs.

Core-sheath co-extrusion produces bi-component fibers with continuous PCM core and polymeric sheath. Vigo et al. ${ }^{[28]}$ first filled hollow fiber with phase change salts by impregnation to obtain temperature-sensitive fiber. However, hollow fiber impregnation is rather inefficient. Recently a novel synthetic fluid-core filament (LCF), comprising a thermoplastic polymer sheath and a microscale liquid core, has been developed with high-speed spinning at the pilot scale ${ }^{[29]}$. The continuous in-line filling of the filament could be achieved by equipping a melt-spinning line with a special spin pack that allowed the injection of a liquid fed from a high-performance fluid pump directly into the polymer melt stream ${ }^{[30]}$. Liquids in the core of a synthetic filament can provide unprecedented properties to textiles, without compromising mechanical properties, dyeability or washability ${ }^{[31]}$.

PCMs usually have low thermal conductivity in the range between 0.1 and $1 \mathrm{~W} \mathrm{~m}^{-}$ ${ }^{1} \mathrm{~K}^{-1}[\underline{32}]$. Low thermal conductivity of PCMs strongly decreases the thermal conversion rates, thus limiting its application scope. Thermal conductivity of PCMs has been enhanced by dispersing filler with high thermal conductivity into PCMs, such as graphene ${ }^{[33]}$, carbon nanotubes ${ }^{[20]}$, metal nanoparticles ${ }^{[14]}$ and metallic compound ${ }^{[34]}$. Although the thermal conductivity of PCMs could be improved in this way, effective 
dispersion is very difficult to achieve because of the large surface area and high surface energy of the particles $[35]$.

Here, we prepared flexible phase change filaments with core-sheath structure by filling hollow fibers with IL. The polymeric sheath prevents against water and serves as supporting material. In order to reduce supercooling degree, as well as to enhance the thermal conductivity of $\mathrm{IL}, \mathrm{Cu}$ decorated muscovite was prepared via in situ reduction and was added to the core component.

\section{Experimental}

\subsection{Materials}

Copper (II) sulfate pentahydrate $\left(\mathrm{CuSO}_{4} \cdot 5 \mathrm{H}_{2} \mathrm{O}\right.$, AR) and citric acid $\left(\mathrm{C}_{6} \mathrm{H}_{8} \mathrm{O}_{7} \cdot \mathrm{H}_{2} \mathrm{O}\right.$, AR) were purchased from Shanghai Rich Joint Chemical Reagents CO., Ltd (Shanghai, China). Sodium hypophosphite $\left(\mathrm{NaH}_{2} \mathrm{PO}_{2} \cdot \mathrm{H}_{2} \mathrm{O}, \mathrm{AR}\right)$ was supplied by $\mathrm{Da}$ 'mao Chemical Reagent Factory (Tianjin, China). Muscovite (MVT) was supplied by Guangzhou Hong Chuang Trade Co., Ltd (Guangzhou, China). Polyvinyl pyrrolidone K30 (PVP K30, purity 97\%, Shanghai Bo'ao Biological Technology Co., Ltd., Shanghai, China) was used as dispersing agent. 1-Butyl-4-methylpyridinium hexafluoro-phosphate (IL) (purity $\geq 97.0 \%$, Sigma-Aldrich, Shanghai, China) was used as core component.

Polypropylene (PP) H 10099 with a melt flow index (MFI) of $35 \mathrm{~g} / 10 \mathrm{~min}$ (at $230^{\circ} \mathrm{C}$ and $2.16 \mathrm{~kg}$ ) and a density of $0.905 \mathrm{~g} / \mathrm{cm}^{3}$, was purchased from Total Petrochemicals and was used to spin the hollow PP filament. 


\subsection{Polypropylene hollow filament preparation}

Polypropylene hollow filament (PP) was prepared on a customized pilot meltspinning plant originally built by Fourné Polymertechnik (Alfter-Impekoven,

121 Germany). Further details about the melt-spinning plant can be found elsewhere $[\underline{36]}$.

122 Prior to extrusion, PP was vacuum dried for $12 \mathrm{~h}$ at $70^{\circ} \mathrm{C}$. A single screw extruder with

$12314 \mathrm{~mm}$ diameter and a length to diameter ratio of 25 was used to melt and feed the 124 polymer to a melt pump that in turn supplied the polymer melt at a fixed throughput to the spin pack. Extruder pressure needed for an effective operation of the melt pump was 60 bar, extruder and spin pack temperatures between 165 and $180{ }^{\circ} \mathrm{C}$, and the nominal throughput of the gear pump was $7.5 \mathrm{~cm}^{3} / \mathrm{min}$. The filament was spun through an annular core-sheath monofilament die that consisted of a tube with $0.6 \mathrm{~mm}$ inner diameter and $0.9 \mathrm{~mm}$ outer diameter within a $1.2 \mathrm{~mm}$ capillary. Pressurized air was used to assist the formation and stabilization of the hollow core. Finally, the filaments were solidified by air quenching at $10{ }^{\circ} \mathrm{C}$ and collected as-spun (i.e. without drawing). The resulting hollow filament has a linear density of $0.1 \mathrm{mg} / \mathrm{m}$ (1 dtex), and an inner and outer diameter of $\sim 0.85 \mathrm{~mm}$ and $\sim 0.95 \mathrm{~mm}$, respectively.

\subsection{Preparation of PCMs}

\subsubsection{Preparation of Cu-MVT}

To prepare copper nanoparticle decorated muscovite (Cu-MVT), a simple in situ reduction method was conducted as follows ${ }^{[37]}$ : First, $1.25 \mathrm{~g}$ of $\mathrm{CuSO}_{4} \cdot 5 \mathrm{H}_{2} \mathrm{O}$ and 0.6 
$\mathrm{g}$ of PVP were dissolved in $20 \mathrm{~mL}$ deionized water. Then the $\mathrm{CuSO}_{4}$ solution was mixed with $0.6 \mathrm{~g}$ muscovite in a $100 \mathrm{~mL}$ conical flask by magnetic stirring for $10 \mathrm{~min} .1 .56 \mathrm{~g}$ of $\mathrm{NaH}_{2} \mathrm{PO}_{2} \cdot \mathrm{H}_{2} \mathrm{O}$ and $0.405 \mathrm{~g}$ of Citric Acid were dissolved in $60 \mathrm{~mL}$ deionized water and then added into the conical flask. The mixture was stirred at a constant temperature of $70{ }^{\circ} \mathrm{C}$ for $4 \mathrm{~h}$. The reaction product was filtered and washed with deionized water repeatedly until the $\mathrm{pH}$ value of the filtrate was $\sim 7$. Finally, the Cu-MVT was dried in a vacuum oven at $100{ }^{\circ} \mathrm{C}$ for $24 \mathrm{~h}$.

\subsubsection{Preparation of IL-filled filament}

$6 \mathrm{~g}$ of IL was mixed with $0.6 \mathrm{~g}$ Cu-MVT and MVT, respectively, by magnetic stirring for $1 \mathrm{~h}$ and ultrasonic dispersion for $0.5 \mathrm{~h}$ both at $60{ }^{\circ} \mathrm{C}$. The obtained $\mathrm{Cu}-$ MVT/IL and MVT/IL mixture as well as pure IL, were injected into the polypropylene hollow filaments using a high precision injection pump (LSP01-1BH, Longer Precision Pump Co., Ltd) with a $10 \mathrm{~mL}$ syringe, respectively. The injection was conducted in an oven at $100{ }^{\circ} \mathrm{C}$ under nitrogen atmosphere to prevent the solidification of IL. Finally, the ends of the IL-filled filaments were sealed using a hot blade.

\subsection{Characterization}

The surface morphology of samples were recorded by a Scanning Electron Microscope (NOVA NANOSEM 430, FEI, USA) equipped with an energy dispersive X-ray (EDX) fluorescence spectroscopy to determine surface elements. ICP-AES (Leeman Labs Prodigy 7, USA) and X-ray Photoelectron Spectrometer (XPS) (Axis 
Ultra DLD, Kratos, UK) were used in the content and chemical state analysis of copper in Cu-MVT. X-ray diffraction (XRD) patterns were recorded with an X-ray Diffractometer (X'Pert Pro, PANalytical, Netherlands) under $\mathrm{Cu} \mathrm{K} \alpha$ radiation (wave length $=0.1541 \mathrm{~nm}, 40 \mathrm{kV}$ and $100 \mathrm{~mA}$ ) at a scanning rate of $4 \% \mathrm{~min}$ in the $2 \theta$ range of $5 \sim 90^{\circ}$. Thermal conductivity measurements were performed with a Laser Thermal Conductivity Tester (LFA447/2-4, NETZSCH, Germany) at $25^{\circ} \mathrm{C}$. Five measurements per sample were conducted and the average values were reported. The chemical characterization of PCMs was performed by Fourier Transform Infrared Spectroscopy (MAGNA 760 model, Nicolet Instrument, USA) in the range of $400 \sim 4000 \mathrm{~cm}^{-1}$ at room temperature using $\mathrm{KBr}$ pellets. The thermal stability of IL, IL/PP, MVT/IL/PP and CuMVT/IL/PP were investigated using a Thermo-Gravimetric Analyzer (TG209F1, NETZSCH, Germany). The measurements were conducted at a temperature rate of $10{ }^{\circ} \mathrm{C} / \mathrm{min}$ in the range of $30 \sim 700{ }^{\circ} \mathrm{C}$ under nitrogen atmosphere.

The phase change properties of IL, IL/PP, MVT/PP and Cu-MVT/IL/PP were measured using a Differential Scanning Calorimeter (DSC204F1, NETZSCH, Germany). A tested sample was heated from room temperature up to $250^{\circ} \mathrm{C}$ at a rate of $10^{\circ} \mathrm{C} / \mathrm{min}$ under nitrogen gas (1st heating). After 5 minutes at isothermal condition, a cooling ramp of $20^{\circ} \mathrm{C} / \mathrm{min}$ was conducted down to $20^{\circ} \mathrm{C}$ (1st cooling), followed by a second heating ramp of $20^{\circ} \mathrm{C} / \mathrm{min}$ up to $250^{\circ} \mathrm{C}$ (2nd heating).

Tensile experiments were conducted using a single yarn strength tester (YG021, Changzhou Second Textile Instrument Factory CO., Ltd (China) in accordance with ASTM D3822 standard. 


\section{Results and discussion}

\subsection{Characterization of Cu-MVT}

Fig.1 shows the SEM images of MVT and Cu-MVT. As shown in Fig. 1(a), the MVT powder is composed of irregular flakes with a particle size of $10 \sim 40 \mu \mathrm{m}$. Some exfoliated debris is also seen at higher magnification (Fig. 1(b)). This kind of morphology can provide a rich interface for the nucleation of phase change materials. Muscovite consists of $\mathrm{O}, \mathrm{Al}, \mathrm{Si}$ and $\mathrm{K}$ as indicated by EDX analysis in Table 1 (Spectrum 1). In Fig. 1(b), nanoparticles in 100 300 nm are densely dispersed on the surface of muscovite. These nanoparticles consist of $\mathrm{Cu}$ as dictated by the comparison of the element content of Spectrum 3 with Spectrum 2 in Table 1, showing that $\mathrm{Cu}$ nanoparticles were successfully coated on the muscovite. Compared to the SEM image of the mixture of $\mathrm{Cu}$ and MVT (Fig. 1(i)), copper nanoparticles disperse much better in area, it can be concluded that the coated copper predominantly existed in $\mathrm{Cu}(0)$ form 


\subsection{Characterization of $\mathrm{Cu}-\mathrm{MVT} / \mathrm{IL}$ composite}

207

208

209

210

211

212

\subsubsection{XRD analysis}

The XRD patterns of MVT, Cu-MVT, IL and Cu-MVT/IL are shown in Fig. 2(a). The peaks in the X-ray patterns of the MVT sample match muscovite (JCPDS 72-1503). A few amount of $\mathrm{SiO}_{2}$ is also found in the MVT sample according to the peaks at $2 \theta=$ $20.8^{\circ}$. As seen in the X-ray pattern of Cu-MVT, three additional peaks at around $43^{\circ}$, $50^{\circ}$ and $70^{\circ}$ can be assigned to the $\mathrm{Cu}^{0}$ crystal (JCPDS 65-9026), corresponding to the reflections of (111), (200) and (220), respectively. The average crystallite size $D(\mathrm{~nm})$ of $\mathrm{Cu}^{0}$ can be evaluated by the Scherrer formula $D=K \lambda /(B \cos \theta)$, where $K=0.89$ is Scherrer constant, $\lambda$ signifies the $x$-ray wavelength, $B$ is the half width of the diffraction peak, and $\theta$ is the Bragg's diffraction angle ${ }^{[39]}$. Thus, D is calculated to be $32.38 \mathrm{~nm}$, much smaller than the size shown in SEM, indicating that the copper particle attached to the muscovite is the aggregation of single crystal. All the characteristic peaks of IL and $\mathrm{Cu}-\mathrm{MVT}$ were observed in the curve of the $\mathrm{Cu}-\mathrm{MVT} / \mathrm{IL}$ composite at the same position. However, the strongest diffraction peak of IL was observed at $19.90^{\circ}$ while the strongest peak of IL in $\mathrm{Cu}-\mathrm{MVT} / \mathrm{IL}$ was shown at $12.15^{\circ}$. Orientation of IL crystals or crystal transformation may happen due to the interaction between IL and Cu-MVT $[\underline{40}, \underline{41]}$. Thus the diffraction strength of peaks at different diffraction angle changes.

\subsubsection{FTIR analysis}

Fig. 2(b) shows the FTIR spectra of MVT, Cu-MVT, IL and Cu-MVT/IL. The 
strong absorption peak at $3600 \mathrm{~cm}^{-1}$ is assigned to the $\mathrm{OH}$ stretching vibration of muscovite (MVT). The peaks observed at $1032 \mathrm{~cm}^{-1}$ and $787 \mathrm{~cm}^{-1}$ correspond to the SiO-Si asymmetric and symmetric stretching vibration, respectively, which are characteristic peaks of silicate ${ }^{[42]}$. As seen in the spectrum of Cu-MVT, a new peak appears at $1664 \mathrm{~cm}^{-1}$, which is attributed to the $\mathrm{C}=\mathrm{O}$ stretching vibration of the dispersing agent PVP. In the FTIR spectrum of IL, the peaks at $3139 \mathrm{~cm}^{-1}$ and $3075 \mathrm{~cm}^{-}$ ${ }^{1}$ are assigned to the $\mathrm{C}-\mathrm{H}$ stretching vibrations of the pyridine ring, while the peaks at $2966 \mathrm{~cm}^{-1}$ and $2878 \mathrm{~cm}^{-1}$ show the $\mathrm{C}-\mathrm{H}$ stretching vibrations of side-chain alkyl. The bands at about $1577 \mathrm{~cm}^{-1}$ and $1473 \mathrm{~cm}^{-1}$ can be assigned to pyridine skeleton vibration, and the peaks at $838 \mathrm{~cm}^{-1}$ and $558 \mathrm{~cm}^{-1}$ to $\mathrm{P}-\mathrm{F}$ stretching vibration and bending vibration, respectively ${ }^{[43]}$. The strong bands at $3673.95 \mathrm{~cm}^{-1}$ and $3594.61 \mathrm{~cm}^{-1}$ are and IL. However, some shifts of the main peaks were found compared to CoPA. The peaks of hydrogen bond of IL shifts from $3673.95 \mathrm{~cm}^{-1}$ to 3678.58 , and from 3594.61

$243 \mathrm{~cm}^{-1}$ to $3599.07 \mathrm{~cm}^{-1}$. Because hydrogen bond exists in both IL and Cu-MVT, new type 244 of hydrogen bond like $\mathrm{OH} \cdots \mathrm{F}-\mathrm{P}$ can be formed between IL and Cu-MVT, which leads to the frequency shifts ${ }^{[45]}$. 


\subsection{Thermal properties}

\subsubsection{Thermal conductivity}

Thermal conductivity is an important property for phase change heat storage, as low conductivity leads to hysteresis of the thermal response. The measured thermal conductivities of IL, MVT, MVT/IL and Cu-MVT/IL are shown in Fig. 3. Pure ionic liquid shows a poor thermal conductivity of only $0.186 \mathrm{~W} \mathrm{~m}^{-1} \mathrm{~K}^{-1}$. The thermal conductivity of MVT/IL is only slightly improved, because the thermal conductivity of muscovite is not much higher than that of IL, as depicted in Fig. 5. In contrast, the thermal conductivity of the $\mathrm{Cu}-\mathrm{MVT} / \mathrm{IL}$ shows a two-fold increase $\left(0.370 \mathrm{~W} \mathrm{~m}^{-1} \mathrm{~K}^{-1}\right)$ compared to IL. The increase of thermal conductivity of Cu-MVT/IL can be explained by the high thermal conductivity of the $\mathrm{Cu}$-coated muscovite $\left(3.026 \mathrm{~W} \mathrm{~m}^{-1} \mathrm{~K}^{-1}\right)$ and the good dispersion of $\mathrm{Cu}$ by preloading via in-situ reduction. The thermal conductivity of $\mathrm{Cu}-\mathrm{MVT} / \mathrm{IL}\left(0.370 \mathrm{~W} \mathrm{~m}^{-1} \mathrm{~K}^{-1}\right)$ is higher than most of composite PCMs, such as

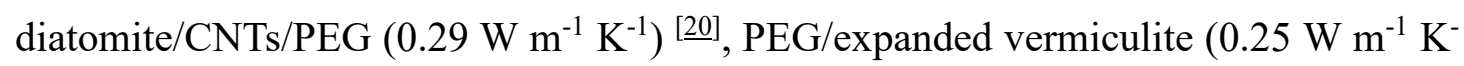
$\left.{ }^{1}\right)^{[46]}$, galactitol hexa myristate/diatomite $\left(0.19 \mathrm{~W} \mathrm{~m}^{-1} \mathrm{~K}^{-1}\right)^{[47]}$.

\subsubsection{Thermal storage properties}

Fig. 4 shows the DSC thermograms for pure IL, IL/PP, MVT/IL/PP and $\mathrm{Cu}-$ MVT/IL/PP. The crystallization peak temperature $\left(T_{\mathrm{c}}\right)$, crystallization enthalpy $\left(\Delta H_{\mathrm{c}}\right)$, melting peak temperature $\left(T_{\mathrm{m}}\right)$, and melting enthalpy $\left(\Delta H_{\mathrm{m}}\right)$ of the different PCMs are listed in Table 2. The encapsulation ratio $(R)$ of the PCM composites can be calculated from following equation: 
$R=\frac{\Delta H_{m, 1}}{\Delta H_{m, 2}} \times 100 \%$

where $\Delta H_{\mathrm{m}, 1}$ and $\Delta H_{\mathrm{m}, 2}$ are the melting enthalpies of PCM composite and pure ionic liquid, respectively.

As a result, all encapsulation ratios of the PCM composites are exceeding 92\% (Table 2). In the DSC curve of the cooling step of pure IL (Fig. 4(a)), no crystallization peak appears in the temperature range of $-40 \sim 70{ }^{\circ} \mathrm{C}$ at a cooling rate of $10{ }^{\circ} \mathrm{C} / \mathrm{min}$. In contrast, binary cold crystallization peaks show in the second heating step followed by a melting peak at $44.9{ }^{\circ} \mathrm{C}$ (Fig. 4(b)). This unusual phase transition behavior confirms the supercooling of ionic liquids. Due to the high supercooling degree of the IL, imperfect crystal can form in cold crystallization, leading to binary peaks. The DSC curve of the IL/PP filament is similar to IL, with slightly smaller melting enthalpy due to the supporting PP filament that undergoes no phase change process in this temperature range. Only one cold crystallization peak of IL/PP was shown in the heating step, which can be attributed to the change of thermal conductivity or physical interaction ${ }^{[48]}$. And The heterogeneous nucleation effect of PP might lead to more perfect crystal of IL, which is responsible for the increase of $T_{\mathrm{m}}$. Both MVT/IL/PP and $\mathrm{Cu}-\mathrm{MVT} / \mathrm{IL} / \mathrm{PP}$ display crystallization peaks in the cooling step due to the addition of a nucleating agent. And MVT/IL/PP still displays a weak cold crystallization peak. The extent of supercooling can be calculated from the difference of melting and crystallization temperature, and the corresponding values for $\mathrm{MVT} / \mathrm{IL} / \mathrm{PP}$ and $\mathrm{Cu}-$ MVT/IL/PP are $60.8{ }^{\circ} \mathrm{C}$ and $42.8{ }^{\circ} \mathrm{C}$, respectively, indicating that $\mathrm{Cu}-\mathrm{MVT}$ is the favored nucleating agent for IL. This can be explained by that Cu-MVT provides 
affiliative surface for IL nucleation and promotes heat transfer at the same time as thermal conductivity has been improved $[\underline{46}, \underline{49}, \underline{50}$. Moreover, with the introduction of the nucleating agent, the IL content can be decreased. However, melting enthalpies of MVT/IL/PP (52.66 J/g) and Cu-MVT/IL/PP (52.68 J/g) are slightly higher than that of IL/PP (52.39 J/g), which also indicates that MVT and Cu-MVT promote the thermal storage performance of IL. Due to the high supercooling degree of IL, the measured melting enthalpy of IL is lower than the theoretical value. The introduction of MVT or $\mathrm{Cu}$-MVT decreases the supercooling degree, and more perfect crystals form in the cooling step.

\subsubsection{Thermal durability}

To examine the thermal durability of $\mathrm{Cu}-\mathrm{MVT} / \mathrm{IL} / \mathrm{PP}$ PCMs, a thermal test with 20 cycles was carried out under air atmosphere. Fig. 5 shows the DSC curves of IL and $\mathrm{Cu}-\mathrm{MVT} / \mathrm{IL} / \mathrm{PP}$ before and after thermal cycling. In the DSC curve of IL (Fig. 5(b)), no phase transition appears, indicating that IL loses its thermal storage ability after thermal cycling. This could be ascribed to adsorption of $\mathrm{H}_{2} \mathrm{O}$ from moist air. In contrast, $\mathrm{Cu}-$ MVT/IL/PP exhibits a good durability, as shown in Fig. 5(d). Even after 20 thermal cycles, the melting temperature and crystallization temperatures were changed by only $0.5^{\circ} \mathrm{C}$ and $0.9^{\circ} \mathrm{C}$, respectively. Regarding to latent heat, the melting latent heat and crystallization latent heat decreased by $0.8 \%$ and $1.5 \%$, respectively. These small changes can be neglected for latent heat storage. The improved durability can be attributed to the protection by the sheath polymer and the chemical compatibility 
between $\mathrm{Cu}-\mathrm{MVT}$ and IL.

\subsubsection{Thermal stability}

The thermal stabilities of pure IL, MVT, PP hollow fiber, IL/PP, MVT/IL/PP and Cu-MVT/IL/PP composites were investigated by TGA. As shown in Fig. 6(a) and Table 3, only one weight loss step can be observed for all samples. The pure ionic liquid and the hollow fiber start to decompose at (weight loss of $5 \%$ ) $327.0^{\circ} \mathrm{C}$ and $396.8^{\circ} \mathrm{C}$, respectively, and the final weight loss percentages of both materials are near to $100 \%$. The weight loss of the IL/PP filament starts within the temperature range of 341.2 457. $5^{\circ} \mathrm{C}$, indicating that the polymeric sheath can enhance the thermal stability of the ionic liquid. The mass losses of MVT/IL/PP and Cu-MVT/IL/PP start at $320.0{ }^{\circ} \mathrm{C}$ and $318.8^{\circ} \mathrm{C}$, respectively, which are lower than the degradation temperature of IL/PP. FTIR analysis have suggested that hydrogen bond exists between IL and MVT. The decrease of $T_{\text {onset }}$ can be attributed to the interaction between IL and MVT at high temperature. It is worth noting that a new peak was appeared at $\sim 430{ }^{\circ} \mathrm{C}$ in the DTG curve of $\mathrm{Cu}-\mathrm{MVT} / \mathrm{IL} / \mathrm{PP}$ compared to that of MVT/IL/PP. Previous studies have revealed that copper can promote the formation of carbon in the degradation process of organics $\left[\frac{51-53]}{}\right.$. Thus the new peak can be derived from the catalyzing carbonization of copper. In this study, the designed working temperature of $\mathrm{Cu}-\mathrm{MVT} / \mathrm{IL} / \mathrm{PP}$ is usually below $100{ }^{\circ} \mathrm{C}$, which is far lower than the degradation temperature. In addition, the corresponding residual masses of $\mathrm{MVT} / \mathrm{IL} / \mathrm{PP}$ and $\mathrm{Cu}-\mathrm{MVT} / \mathrm{IL} / \mathrm{PP}$ are $5.94 \%$ and $6.08 \%$, respectively, which can be attributed to muscovite that shows only $2.8 \%$ weight 
loss at $900^{\circ} \mathrm{C}$.

\subsection{Mechanical properties}

In order to evaluate the mechanical property of the ionic liquid-core filaments, tensile experiments were conducted. The respective load-elongation curves of different fiber samples are shown in Fig. 7. All samples display loading-strain tensile curves with three stages typical for semi-crystalline polymers $[\underline{54}, \underline{55]}$ : At the first stage, the force increases linearly with elongation until it reaches a yield point. Necking (stress-induced, abrupt decrease in filament cross-sectional area) appears at the subsequent stage, where the force remains almost constant. At the third stage, when plastic deformation comes to an end, the force increases again until the breaking point is reached. The similar tensile behavior of the different filaments indicates that the sheath polymer (PP) is the main component bearing stress. As can be seen in Table 4, the injection of the IL core results in a decrease of tensile strength and elongation at break. This can either be explained by a certain diffusion of IL into PP, resulting in a weakening of the polymer, and/or a reduction in flexibility due to the solid state of the IL salt, leading to unevenly distributed loads. The sheath polymer of the composite fiber bear extra vertical force from rigid core components. However, with a breaking strength of $1.1 \mathrm{MPa}$ and an elongation at break of $735 \%$, the $\mathrm{Cu}-\mathrm{MVT} / \mathrm{IL} / \mathrm{PP}$ filament still shows good mechanical properties. 


\section{Conclusions}

$\mathrm{Cu}-\mathrm{MVT} / \mathrm{IL} / \mathrm{PP}$ core-sheath filaments were successfully prepared by meltspinning and subsequent filling of hollow monofilaments. Cu-MVT was added to the ionic liquid core acted as nucleating agent. It was shown that the muscovite was coated with spherical-shaped $\mathrm{Cu}^{0}$ particles with a diameter range of 100 300 nm. By mixing $9 \%$ of $\mathrm{Cu}-\mathrm{MVT}$ with the ionic liquid, the thermal conductivity was nearly doubled compared to pure IL. A good chemical compatibility between IL and Cu-MVT was confirmed by XRD and FTIR analysis. DSC results indicate that the Cu-MVT/IL/PP phase change filament melted at $48{ }^{\circ} \mathrm{C}$ with a latent heat of $53 \mathrm{~J} / \mathrm{g}$ and crystallized at $5.5^{\circ} \mathrm{C}$ with a latent heat of $44 \mathrm{~J} / \mathrm{g}$. Owing to the protection by the sheath polymer, the thermal durability of IL was improved significantly as deduced from a 20 cycles thermal test. The Cu-MVT/IL/PP filament also showed good thermal stability and sufficient mechanical properties with a breaking strength of $1 \mathrm{MPa}$ and an elongation at break exceeding $700 \%$.

\section{Acknowledgement}

The authors wish to acknowledge the help of Mathias Lienhard and Benno Wuest for the melt spinning of PP hollow filament spinning. Additionally, a grateful acknowledgement is given to the financial support from the National Nature Science Foundation of China (No. 51873074). 


\section{Key words:}

Phase change materials; Ionic liquid; Supercooling; Muscovite; Core-sheath structure

\section{Reference}

[1] Q. Zhang, Z. He, X. Fang, X. Zhang, Z. Zhang, Energy Storage Materials 2017, 6, 36.

[2] F. Haghighat, S. A. H. Ravandi, M. N. Esfahany, A. Valipouri, Journal of Materials Science 2018, 53, 4665 .

[3] L. Wei, Y. J. Ma, X. F. Tang, J. Nan, Z. Rong, H. Na, X. X. Zhang, Industrial \& Engineering Chemistry Research 2014, 53, 5413.

[4] Y. C. Feng, M. Bodaghi, W. H. Liao, Journal of Applied Polymer Science 2019, 136, 47422.

[5] F. Salaün, E. Devaux, S. Bourbigot, P. Rumeau, Thermochimica Acta 2010, 506, 82.

[6] W. Su, J. Darkwa, G. Kokogiannakis, Renewable \& Sustainable Energy Reviews 2015, 48, 373.

[7] K. R. Seddon, Journal of Chemical Technology \& Biotechnology Biotechnology 2015, 68, 351.

[8] L. Li, H. Li, B. Yan, S. Yu, X. Ge, Journal of Applied Polymer Science 2019, 136, 47058.

[9] S. Alavi, D. L. Thompson, Journal of Chemical Physics 2005, 122, 2038.

[10] S. Chen, H. Liu, S. Liu, P. Wang, S. Zeng, L. Sun, L. Liu, Acs Appl Mater Interfaces 2018, 10.

[11] S. Zhang, N. Sun, X. He, X. Lu, X. Zhang, Journal of Physical \& Chemical Reference Data 2006, $35,1475$.

[12] J. M. Crosthwaite, M. J. Muldoon, J. N. K. Dixon, J. L. Anderson, J. F. Brennecke, Journal of Chemical Thermodynamics 2005, 37, 559.

[13] L. Bai, X. Li, J. Zhu, B. Chen, Energy \& Fuels 2011, 25, 1811.

[14] J. Li, T. Qian, X. Min, W. Guan, Y. Deng, L. Ning, Journal of Materials Chemistry A 2015, 3, 8526.

[15] Y. Deng, J. Li, T. Qian, W. Guan, Y. Li, X. Yin, Chemical Engineering Journal 2016, 295, 427.

[16] D. Gan, S. Lu, C. Song, Z. Wang, European Polymer Journal 2001, 37, 1359.

[17] P. M. Reddy, P. Venkatesu, Journal of Physical Chemistry B 2011, 115, 4752.

[18] Bingjie Sun, Yinan Lin, Peiyi Wu, $\uparrow$ And, H. W. Siesler†, Macromolecules 2008, 41, 1512.

[19] J. Liu, W. Yang, C. Xie, K. Zhang, J. Fan, Journal of Materials Engineering 2015, 43, 42.

[20] A. Sar1, A. Bicer, F. A. Al-Sulaiman, A. Karaipekli, V. V. Tyagi, Energy \& Buildings 2018, 164, 166.

[21] Y. Ma, J. Zong, W. Li, L. Chen, X. Tang, N. Han, J. Wang, X. Zhang, Energy 2015, 87, 86.

[22] G. Fang, H. Li, X. Liu, S. Wu, Chemical Engineering \& Technology 2010, 33, 227.

[23] J. T. Mccann, M. Marquez, Y. Xia, Nano Letters 2006, 6, 2868.

[24] F. Cao, B. Yang, Applied Energy 2014, 113, 1512.

[25] K. Y. Zhu, W. Shuang, Q. I. Heng-Zhi, L. I. Hui, Y. H. Zhao, X. Y. Yuan, Chemical Research in Chinese Universities 2012, 28, 539.

[26] Tang, Xiaofen, Li, Wei, Shi, Haifeng, Wang, Xuechen, Wang, Jianping, Colloid \& Polymer Science 2013, 291, 1705 .

[27] R. Al-Shannaq, J. Kurdi, S. Al-Muhtaseb, M. Dickinson, M. Farid, Energy 2015, 87, 654.

[28] T. L. Vigo, C. E. Frost, Textile Research Journal 1982, 52, 633.

[29] R. Hufenus, L. Gottardo, A. A. Leal, A. Zemp, K. Heutschi, P. Schuetz, V. R. Meyer, M. Heuberger, Materials \& Design 2016, 110, 685.

[30] A. A. Leal, M. Naeimirad, L. Gottardo, P. Schuetz, A. Zadhoush, R. Hufenus, International Journal 
of Polymeric Materials \& Polymeric Biomaterials 2016, 65, 451.

[31] R. Hufenus, A. A. Leal, M. Heuberger, Chemical Fibers International 2018, 4, 181.

[32] H. Ji, D. P. Sellan, M. T. Pettes, X. Kong, J. Ji, L. Shi, R. S. Ruoff, Energy \& Environmental Science 2014, 7, 1185.

[33] D. Zou, X. Ma, X. Liu, P. Zheng, Y. Hu, International Journal of Heat \& Mass Transfer 2018, 120 , 33.

[34] W. L. Wang, X. X. Yang, Y. T. Fang, J. Ding, J. Y. Yan, Applied Energy 2009, 86, 1196.

[35] B. Tang, M. Qiu, S. Zhang, Solar Energy Materials \& Solar Cells 2012, 105, 242.

[36] R. Hufenus, F. A. Reifler, K. Maniura-Weber, A. Spierings, M. Zinn, Macromolecular Materials \& Engineering 2012, 297, 75.

[37] D. Lai, T. Liu, G. Jiang, W. Chen, Journal of Applied Polymer Science 2013, 128, 1443.

[38] H. Dai, H. Li, F. Wang, Surface \& Coatings Technology 2006, 201, 2859.

[39] A. W. Burton, K. Ong, T. Rea, I. Y. Chan, Microporous \& Mesoporous Materials 2009, 117, 75.

[40] T. J. Gannon, A. George Law, P. R. Watson, A. J. C. And, K. R. Seddon, Langmuir 2006, 15, 8429. [41] ROLLINS, B. Julie, FITCHETT, D. Brian, CONBOY, C. John, Journal of Physical Chemistry B 2007, 111, 4990 .

[42] D. Ke, F. Qiu, X. Guo, J. Xu, D. Yang, K. He, Journal of Applied Polymer Science 2013, 129, 1697. [43] H. L. Yang, Z. Y. Zhang, L. Yang, B. H. Zhong, L. Y. Li, X. X. Huang, X. L. Wang, Advanced Materials Research 2011, 236-238, 552.

[44] B. Datta, M. N. Roy, Chemical Physics Letters 2016, 665, 85.

[45] Y. Wu, Y. Xu, D. Wang, Z. Ying, S. Weng, D. Xu, J. Wu, Journal of Applied Polymer Science 2010, 91, 2869.

[46] D. Yong, J. Li, T. Qian, W. Guan, Y. Li, X. Yin, Chemical Engineering Journal 2016, 295, 427.

[47] A. Sar1, A. Biçer, Solar Energy Materials and Solar Cells 2012, 101, 114.

[48] L. Zhang, J. Zhu, W. Zhou, J. Wang, Y. Wang, Energy 2012, 39, 294.

[49] F. Wang, C. Zhang, J. Liu, X. Fang, Z. Zhang, Applied Energy 2017, 188, 97.

[50] C. Wang, L. Feng, W. Li, J. Zheng, W. Tian, X. Li, Solar Energy Materials \& Solar Cells 2012, 105, 21.

[51] G. Fontaine, T. Turf, S. Bourbigot, Acs Symposium 2009, 1013, 329.

[52] H. Lavrenyuk, V. Kochubei, O. Mykhalichko, B. Mykhalichko, Fire Safety Journal 2016, 80, 30.

[53] K. Zhou, S. Jiang, B. Wang, Y. Shi, J. Liu, N. Hong, H. Yuan, G. Zhou, Polymers for Advanced Technologies 2014, 25, 701.

[54] J. Yang, W. J. Liu, G. X. Chen, J. J. Liu, Polymeric Materials Science \& Cngineering 2002, 18, 115. [55] G. Ellson, X. Carrier, J. Walton, S. F. Mahmood, K. Yang, J. Salazar, W. E. Voit, Journal of Applied Polymer Science 2018, 135, 45574. 
Tables:

456 Table 1 Element contents of MVT and Cu-MVT.

\begin{tabular}{|c|c|c|c|c|c|c|c|}
\hline \multirow{2}{*}{ Spectrum point } & \multicolumn{7}{|c|}{ Weight $\%$} \\
\hline & $\mathrm{O}$ & $\mathrm{Al}$ & $\mathrm{Si}$ & $\mathrm{K}$ & $\mathrm{C}$ & $\mathrm{N}$ & $\mathrm{Cu}$ \\
\hline Spectrum 1 & 34.12 & 14.99 & 50.54 & 0.35 & / & / & 1 \\
\hline Spectrum 2 & 42.50 & 12.15 & 18.25 & 6.33 & 17.62 & 0.60 & 2.56 \\
\hline Spectrum 3 & 18.25 & 5.06 & 7.23 & 1.66 & 5.56 & 0.84 & 61.41 \\
\hline
\end{tabular}

457

458 
459 Table 2 Phase change behavior of different PCMs.

\begin{tabular}{llllll}
\hline Samples & $\mathrm{T}_{\mathrm{c}} /{ }^{\circ} \mathrm{C}$ & $\Delta \mathrm{H}_{\mathrm{c}} / \mathrm{J} \mathrm{g}^{-1}$ & $\mathrm{~T}_{\mathrm{m}} /{ }^{\circ} \mathrm{C}$ & $\Delta \mathrm{H}_{\mathrm{m}} / \mathrm{J} \mathrm{g}^{-1}$ & $R / \%$ \\
\hline $\mathrm{IL}$ & $8.6^{*}$ & $48.19^{*}$ & 44.9 & 56.60 & $/$ \\
$\mathrm{IL} / \mathrm{PP}$ & $1.8^{*}$ & $43.78^{*}$ & 48.3 & 52.39 & 92.56 \\
$\mathrm{MVT} / \mathrm{IL} / \mathrm{PP}$ & -13.6 & 28.62 & 47.2 & 52.66 & 93.04 \\
$\mathrm{Cu}-\mathrm{MVT} / \mathrm{IL} / \mathrm{PP}$ & 5.5 & 44.34 & 48.3 & 52.68 & 93.07 \\
\hline
\end{tabular}

$460 *$ cold crystallization.

461 
462 Table 3 Degradation data of weight loss processes.

\begin{tabular}{lllll}
\hline Samples & Onset $/{ }^{\circ} \mathrm{C}$ & Peak $/{ }^{\circ} \mathrm{C}$ & End $/{ }^{\circ} \mathrm{C}$ & Residual mass $/ \%$ \\
\hline $\mathrm{IL}$ & 327.0 & 450.1 & 461.6 & 0.96 \\
$\mathrm{IL} / \mathrm{PP}$ & 341.2 & 440.7 & 457.5 & 0 \\
$\mathrm{PP}$ & 396.8 & 466.7 & 480.4 & 0 \\
$\mathrm{MVT} / \mathrm{IL} / \mathrm{PP}$ & 320.0 & 377.5 & 412.8 & 5.94 \\
$\mathrm{Cu}-\mathrm{MVT} / \mathrm{IL} / \mathrm{PP}$ & 318.8 & 426.0 & 438.5 & 6.08 \\
$\mathrm{MVT}$ & 770.8 & 682.7 & $/$ & 97.2 \\
\hline
\end{tabular}

463

464 
465 Table 4 Tensile properties of different IL-core filaments.

\begin{tabular}{lll}
\hline Samples & Breaking strength/MPa & Elongation at break/\% \\
\hline PP & $1.48 \pm 0.10$ & $980.2 \pm 40.3$ \\
IL/PP & $1.32 \pm 0.13$ & $939.4 \pm 32.8$ \\
MVT/IL/PP & $1.33 \pm 0.03$ & $756.5 \pm 37.6$ \\
$\mathrm{Cu}-\mathrm{MVT} / \mathrm{IL} / \mathrm{PP}$ & $1.31 \pm 0.09$ & $753.8 \pm 31.2$ \\
\hline
\end{tabular}




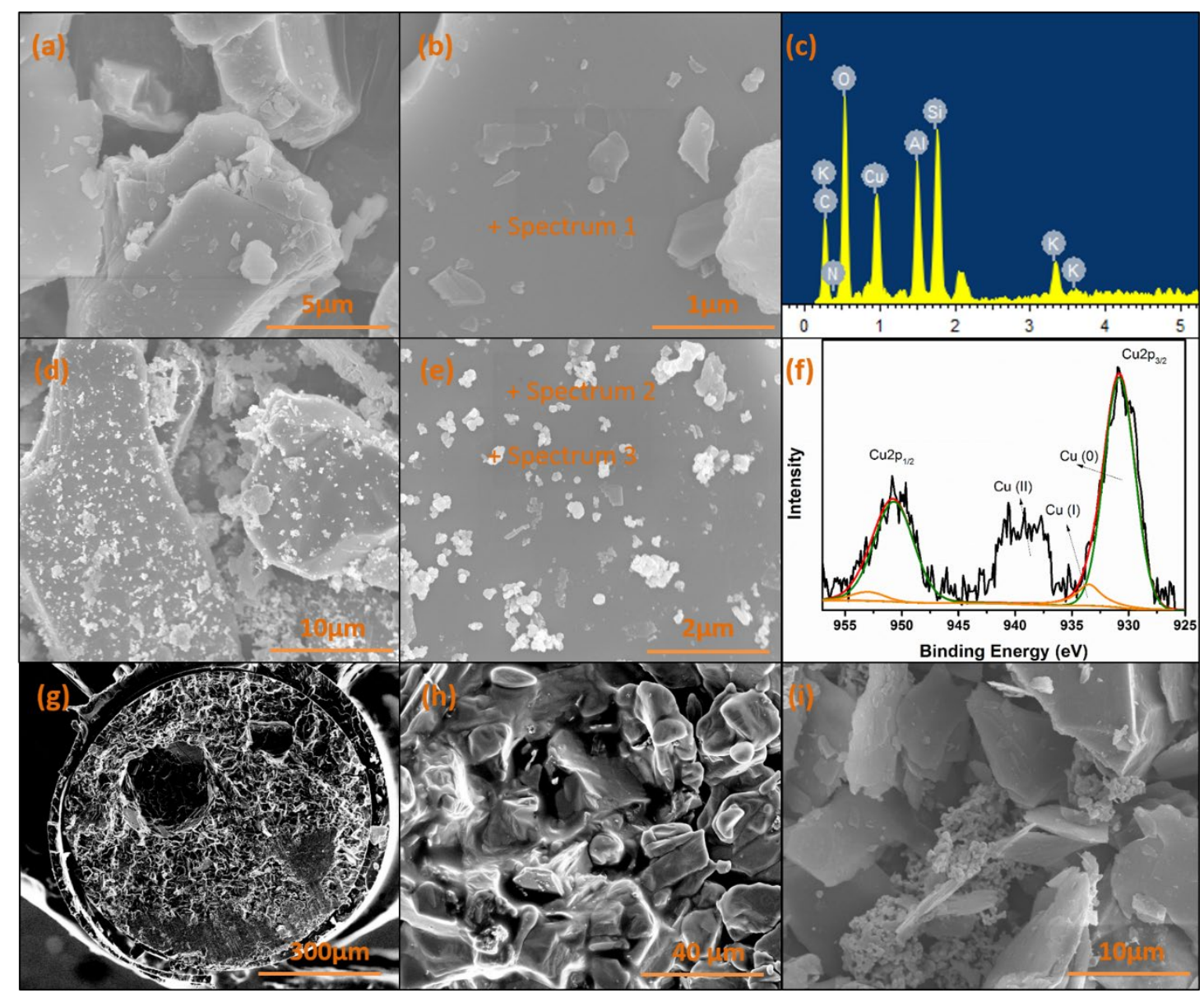

Figure 1. SEM images: (a) MVT mag $20000 \times$, (b) MVT mag $80000 \times$, (d) Cu-MVT mag $10000 \times$, (e) Cu-MVT mag $50000 \times$, (g) Cu-MVT/IL/PP $300 \times$, (h) CuMVT/IL/PP $2500 \times$ and (i) mixture of Cu and MVT $10000 \times$; Spectrum 1, Spectrum 2 and Spectrum 3 are points of EDX analysis.(c) EDX analysis of Spectrum 3. (f) Highresolution XPS spectrum of $\mathrm{Cu} 2 \mathrm{p}$ in the Cu-MVT. 

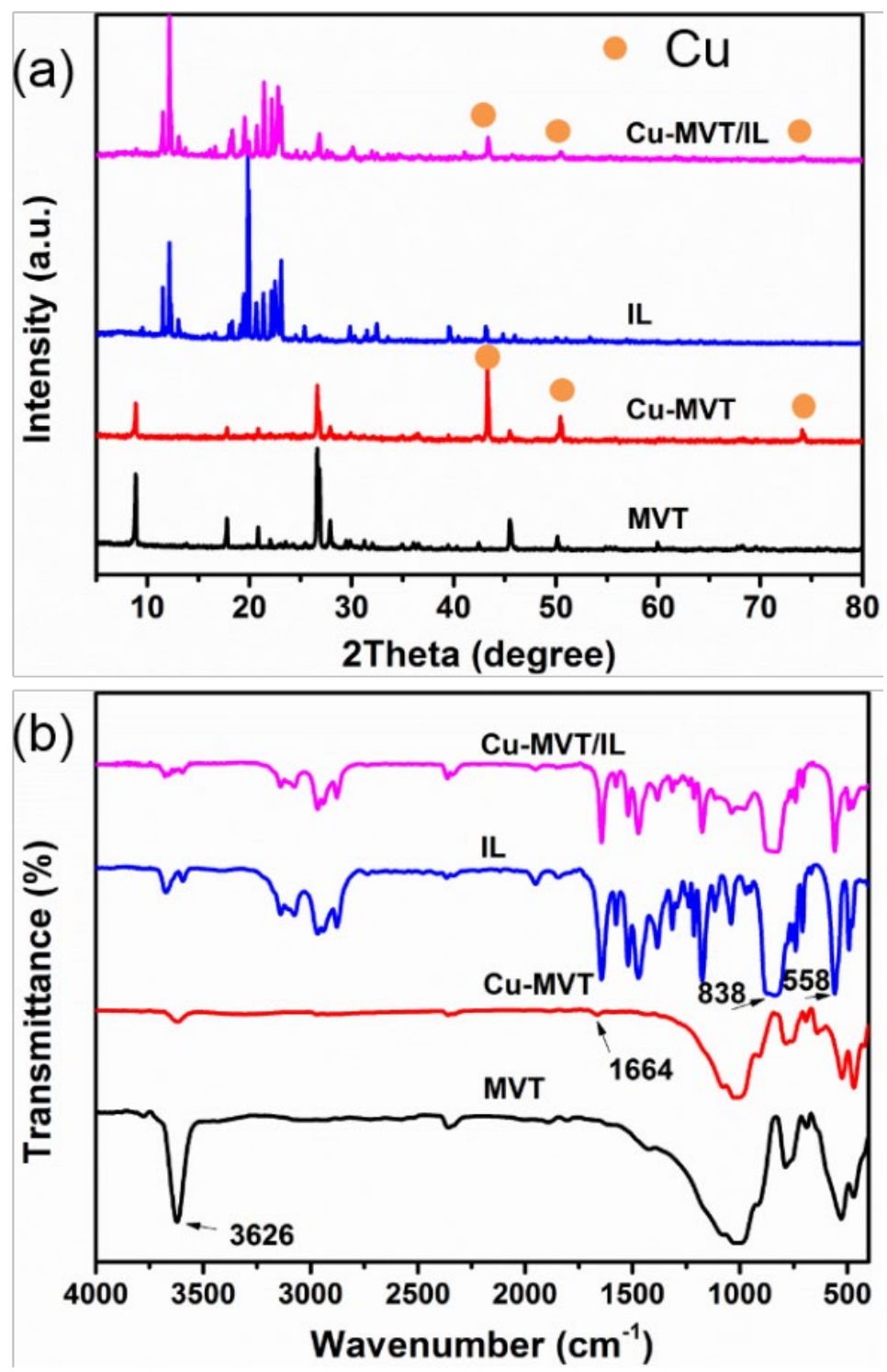

477 Figure 2. (a) XRD patterns and (b) FTIR spectra of MVT, Cu-MVT, IL and CuMVT/IL. 


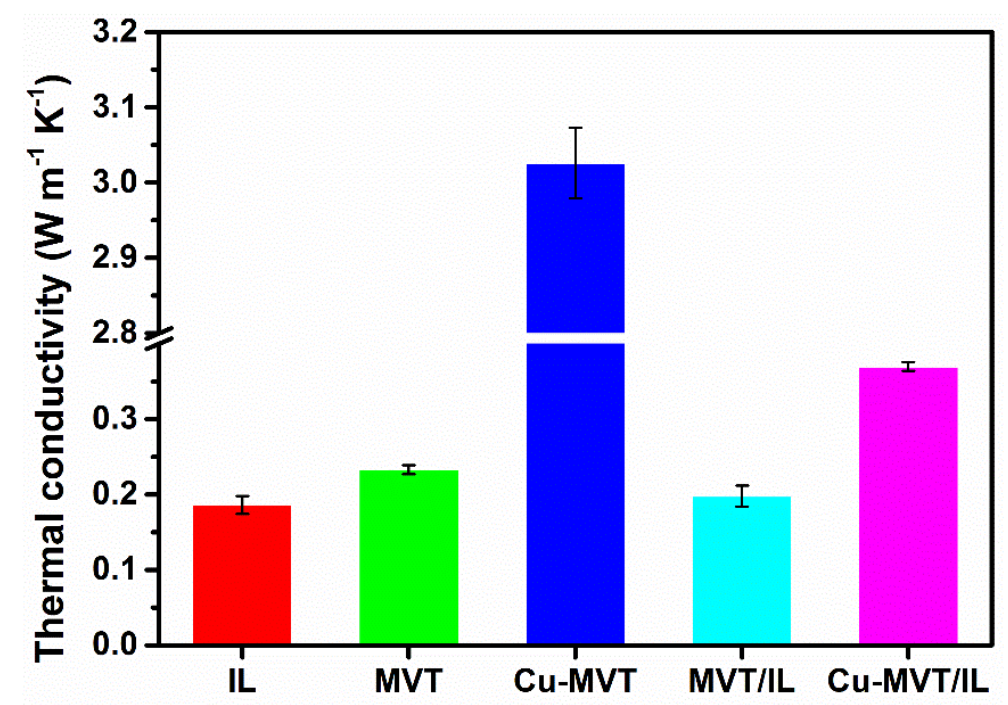

Figure 3. Thermal conductivity values of the samples. 

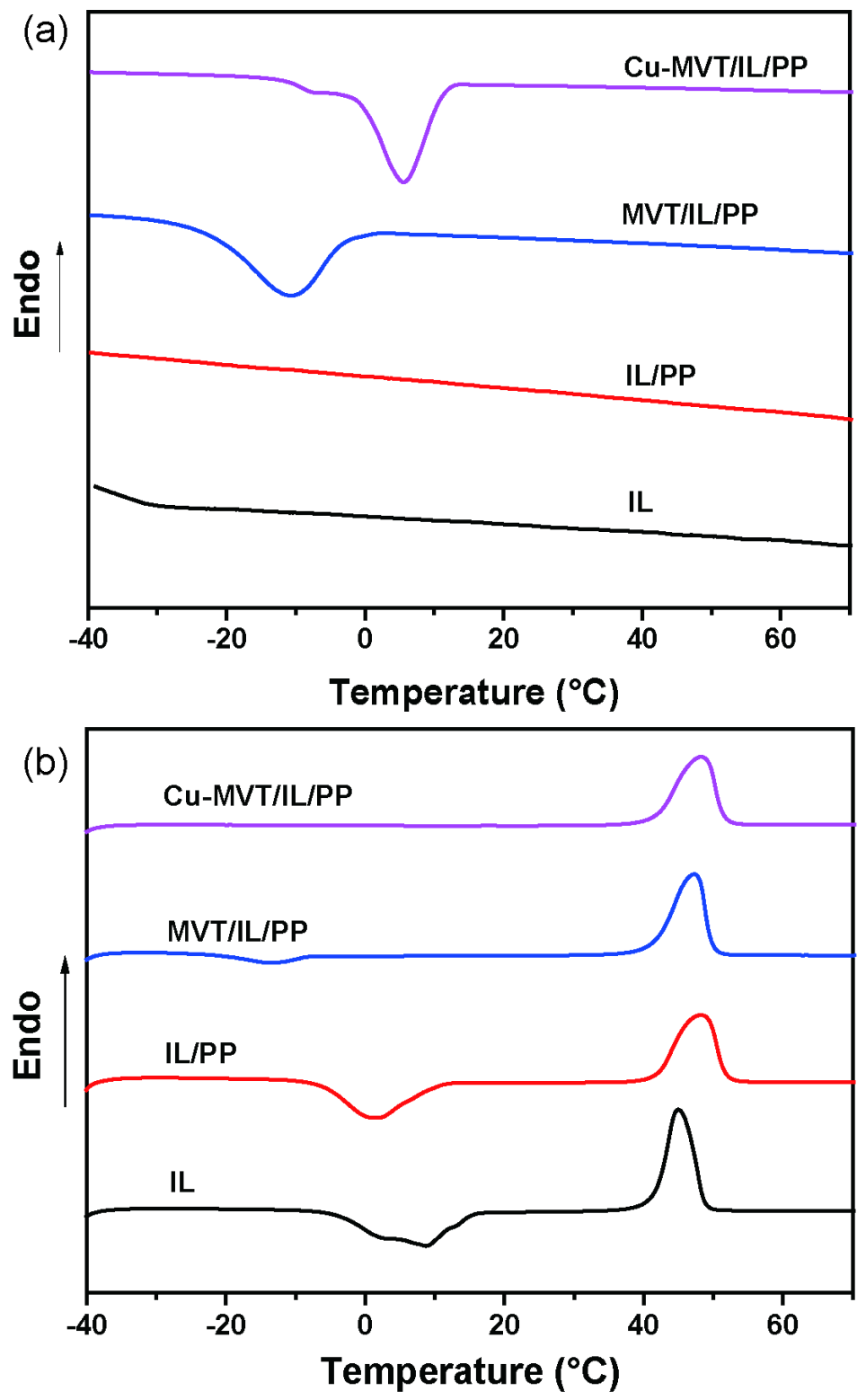

486 Figure 4. DSC curves of different PCMs: (a) cooling step; (b) second heating step. 

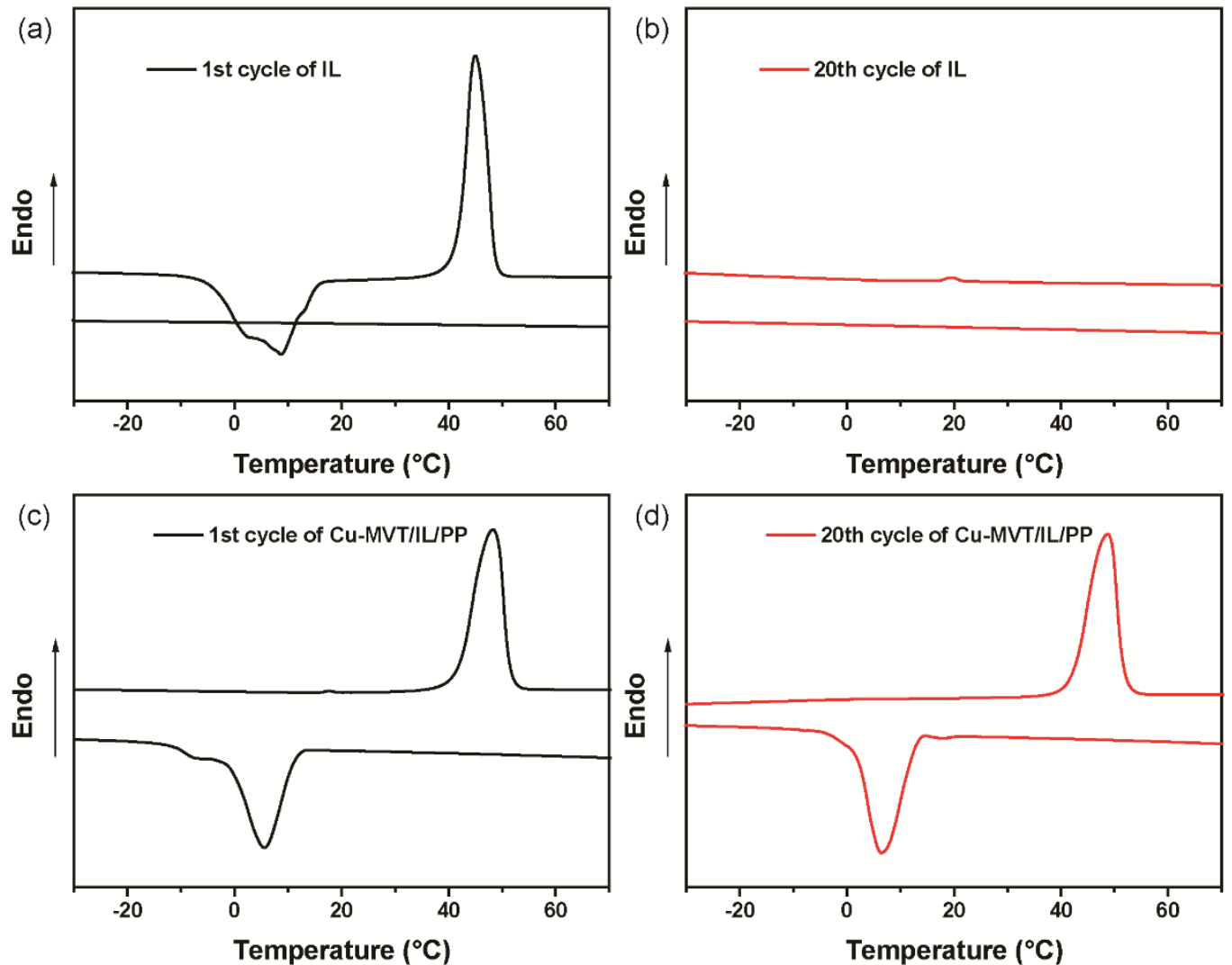

Figure 5. DSC cooling and second heating curves of (a,b) IL and (c, d) Cu- 

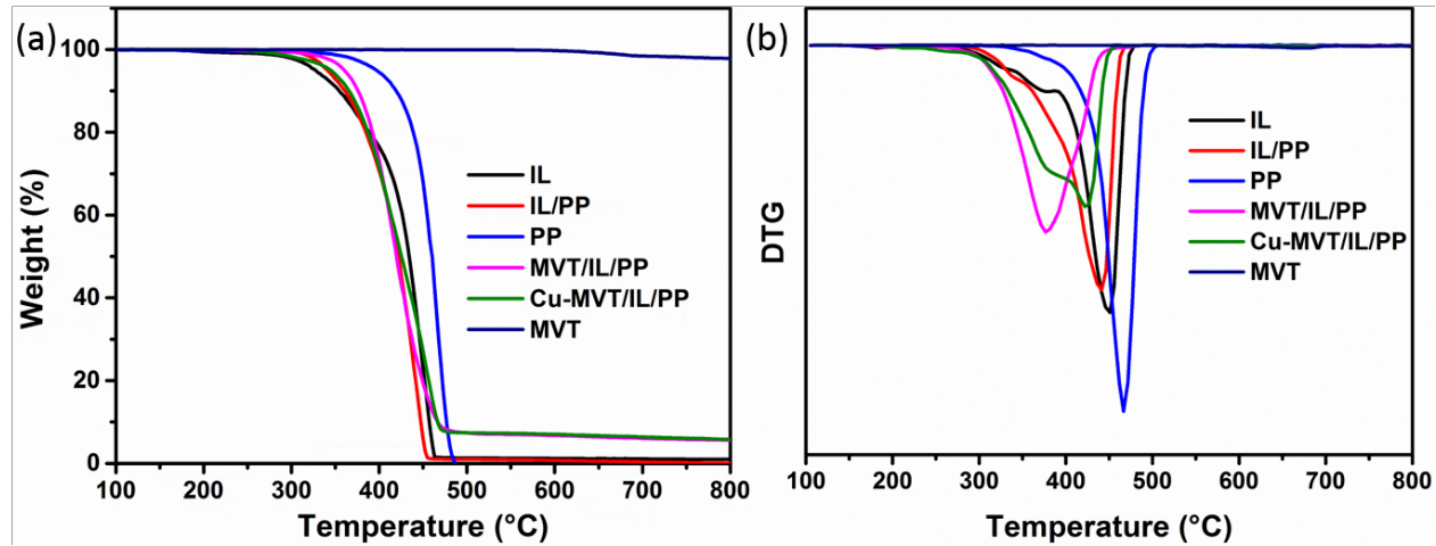

494

Figure 6. (a) TGA and (b) DTG curves of IL and Cu-MVT/IL/PP.

495

496 


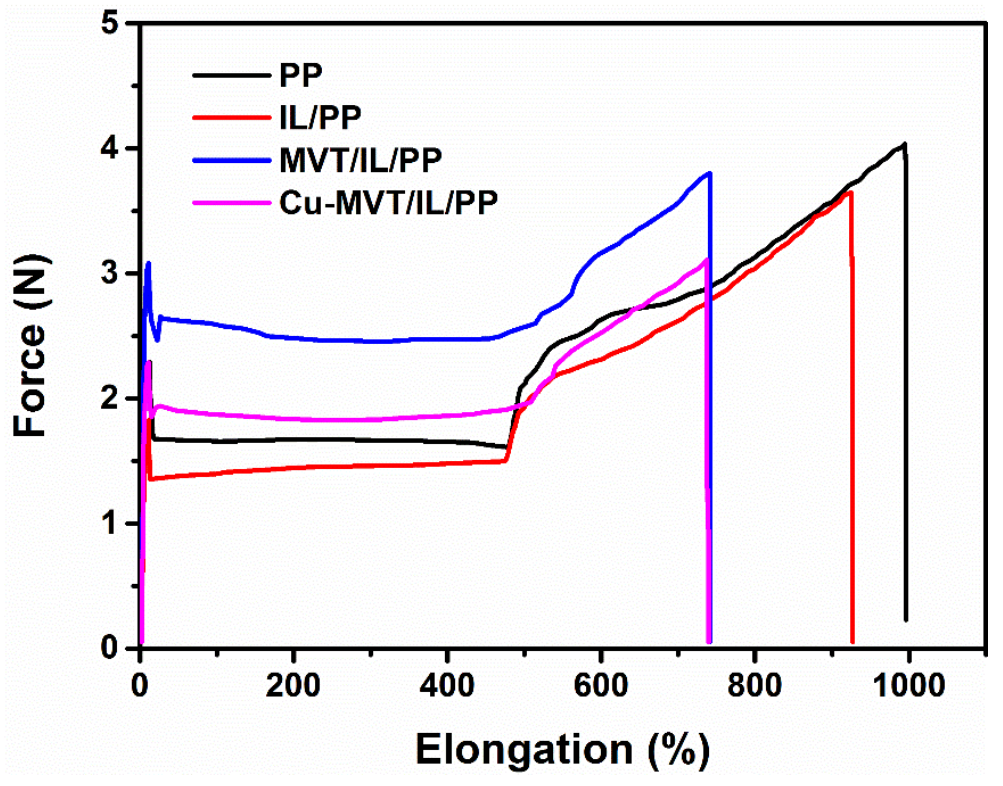

498

Figure 7. load-elongation curves of different IL-core filaments.

499 
Title:

Flexible Phase Change Filament with Ionic Liquid Core

\section{Graphical Abstract Text:}

Shape-stabilized phase change material (PCM) filaments loaded with 93\% ionic liquid were prepared by a simple post-filling method. The ionic liquid core PCM displayed crystallization in the DSC cooling step due to the addition of synthesized copper decorated muscovite. The PCM filament showed good durability, stability and flexibility due to its core-sheath structure

Graphical Abstract Image:

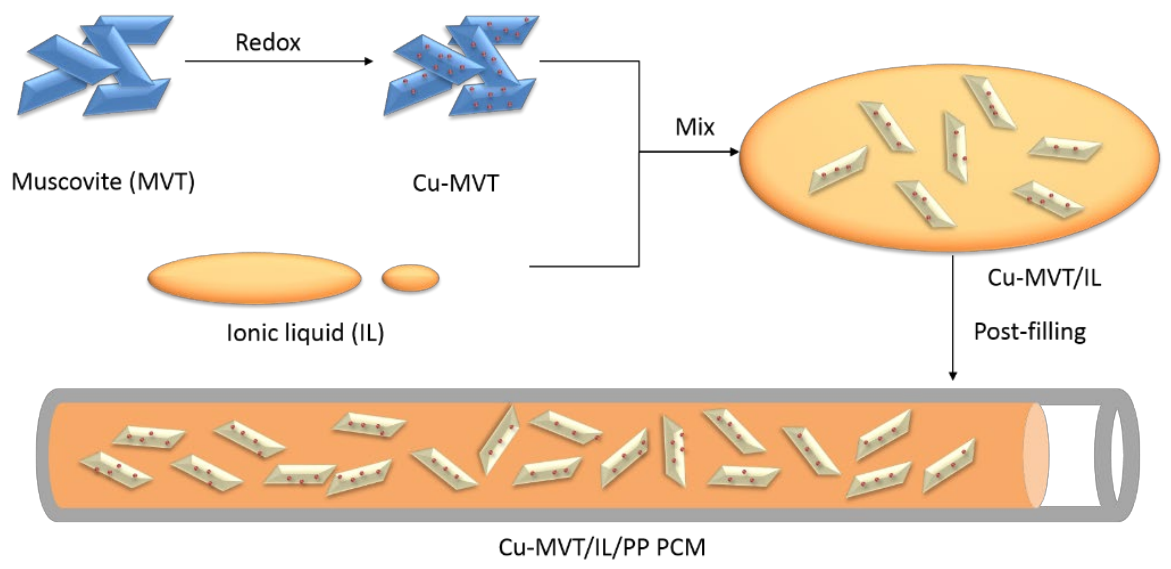

